Article

\title{
Experimental Study of the Relaxation Properties of Carbon Fiber Cloth
}

\author{
Qiang Wang ${ }^{1,2}$, Hua-Lin Song ${ }^{1}$, Chun-Ling Lu ${ }^{1,2,3, * \mathbb{D}}$, Wan-Xu Zhu ${ }^{1,2}$ and Jia-Zhu Huang ${ }^{4}$ \\ 1 College of Civil and Architecture Engineering, Guilin University of Technology, Guilin 541004, China; \\ 2000032@glut.edu.cn (Q.W.); songhualin@glut.edu.cn (H.-L.S.); zhuwanxu@vip.163.com (W.-X.Z.) \\ 2 Guangxi Key Laboratory of New Energy and Building Energy Saving, College of Civil Engineering and \\ Architecture, Guilin University of Technology, Guilin 541004, China \\ 3 Collaborative Innovation Center for Exploration of Nonferrous Metal Deposits and Efficient Utilization of \\ Resources, Guilin University of Technology, Guilin 541004, China \\ 4 Operation department, Guilin High-performance Concrete Materials Technology Limited Liability Company, \\ Guilin 541004, China; hjz15078351070@163.com \\ * Correspondence: 2000013@glut.edu.cn
}

Received: 14 July 2020; Accepted: 12 August 2020; Published: 14 August 2020

\begin{abstract}
In this study, a new method was proposed to study the relaxation properties of carbon fiber reinforced plastics (CFRP) fabric under axial tension. Under the condition of constant temperature and humidity, six groups of $168 \mathrm{~h}$ stress relaxation tests were conducted. Considering the influence of the prestress level, the size of CFRP cloth, and the surface coating of CFRP cloth on the relaxation performance, the measures to reduce the relaxation loss were proposed. The relaxation rate calculation model was established based on the test results of the authors and other scholars and was validated through comparisons with the test results. The results indicate that the relaxation rate of CFRP cloth was between $1.92 \%$ and $6.1 \%$. When the prestress level was smaller than $0.3 \mathrm{fu}$, the relaxation rate of CFRP cloth decreased with the increase of prestress level. When the prestress level was greater than $0.3 \mathrm{fu}$, the relaxation rate increased with the increase of the prestress level. Under the same conditions, the relaxation rate of the CFRP specimens coated with glue was smaller than the uncoated samples by $3.21-6.28 \%$. The calculation model could well estimate the relaxation rate of CFRP cloth.
\end{abstract}

Keywords: carbon fiber cloth; relaxation performance; experimental study; calculation model; prestress loss

\section{Introduction}

Over the past decade, the frequent occurrence of natural disasters has made structural reinforcement a particular concern to countries all over the world. Fiber Reinforced Polymer (FRP) is a composite material composed of load-bearing fibers and a resin matrix. It is light (approximately 0.2 times of the weight of steel). It also has a high tensile strength (1000-5000 MPa for ordinary grade CFRP sheets) and excellent corrosion resistance. The FPR materials can be widely used for structural reinforcement because of their superior performance [1-4]. FRP reinforcement methods are currently applied to four types of FRP materials: aramid fiber-reinforced composite materials (AFRP), basalt fiber-reinforced materials (BFRP), glass fiber-reinforced composite materials (GFRP), and broadly used carbon fiber-reinforced composite materials (CFRP). The CFRP cloth is anisotropic. It is manufactured in bundles of thousands of tiny fibers and woven onto a fabric roll. Researchers have conducted extensive research on the performance of FRP materials to reinforce concrete members [5-8]. Compared with the traditional external FRP reinforcement method, the prestressed FRP technology as an active reinforcement method can avoid the stress-lag effect of the FRP materials. Moreover, 
it takes full advantage of the high-strength characteristics of the FRP materials, enhances the working performance and ultimate strength of the reinforced member, and effectively suppresses the deformation and crack development in the component of interest [9-12]. One of the most prominent problems of the prestressed FRP is stress relaxation, which is attributed to the decrease of stress with time during a constant deformation. To address this well-known problem, the study of the relaxation performance of the prestressed FRP materials, analysis of the relaxation rules and the relaxation quantity, and proposition of measures to reduce the relaxation loss are inevitable. They have to be carried out before applying the prestressed FRP materials for the reinforcement of engineering structures. In recent years, research on the prestressed FRP materials has focused on FRP rebars, FRP plates, and FRP cloth [13]. Saadatmanesh [14] and Tannous [15] studied the relaxation properties of AFRP rebars and CFRP rebars and found that there is a logarithmic relationship between relaxation and time. Through a regression analysis of the test data, Gunnarsson [16] predicted the time-dependent stress relaxation rate of FRP rebars. According to the regression equation obtained, when the initial stress was $0.5 \mathrm{fu}$, the 50 years stress relaxation rate of BFRP rebars was predicted to be $11.2 \%$. This is much larger than the 50 years relaxation rate of BFRP rebars mentioned in the literature. The large difference originates from not considering the potential slippage of the anchor. To eliminate the effect of anchor slippage, Shi et al. [17] developed a test device and investigated the relaxation rate of BFRP rebars when the initial stress was $0.4,0.5$, and $0.6 \mathrm{fu}$. The test results indicate that the stress relaxation coefficients at $1000 \mathrm{~h}$ were $4.2 \%, 5.3 \%$, and $6.4 \%$, respectively. Guo et al. [18] conducted 30 days prestress monitoring on prestressed carbon fiber lamella (CFL) and found that the stress loss rates of the test piece were $1.8 \%, 1.9 \%$, and $2.5 \%$ when the prestress levels were $0.08,0.15$, and $0.22 \mathrm{fu}$, respectively. The stress loss of CFL in the stable stage is related to the magnitude of prestress. The larger is the prestress, the larger is the loss of the prestress in the stable stage. Huang et al. [19] monitored the pre-stress loss tests of a 20 day-old carbon fiber board and performed regression analysis on the test data. The tests indicated that the relaxation loss of the CFRP board increased with the increase of the initial stress and time. In addition, the relaxation loss developed rapidly in the early stage and became steady after $100 \mathrm{~h}$.

Research attempts have been conducted on the loss of prestressed CFRP cloth in strengthened reinforced concrete (RC) members. Kim et al. [20] proposed a closed solution to the stress analysis of the bond interface for the short-term prestress loss of the post-tensioned CFRP cloth in the reinforced prestressed concrete beam. Through calculation, it was found that the prestress loss was about $10 \%$ of the initial prestress. Costa et al. [21] found through experimental observations that the effective stress of prestressed FRP materials is linearly linked to the ambient temperature. Hence, the change of the ambient temperature is the key parameter for the correct evaluation of the effective stress. Zhou et al. [22] reinforced five concrete columns and five steel columns with pre-stressed CFRP fabrics. The pre-stress loss mainly stems from CFRP fabric stress relaxation loss and friction loss. The relaxation loss of CFRP cloth consists of two main components: (1) the stress redistribution due to the mutually coordinated deformation between fibers; and (2) stress relaxation of the carbon fiber itself. Lu et al. [23,24] conducted loss tests on cylindrical and square columns of reinforced concrete reinforced by prestressed CFRP cloth and measured the relaxation loss. The test results suggest that closer to the end of the anchor root there is greater relaxation loss of the fiber cloth. In addition, the lack of friction at the distal end of the fiber cloth anchor root can cause a negative increase in relaxation loss over time. According to the above-mentioned literature reports on the study of stress loss, the method of strengthening the RC member and then analyzing the relaxation loss of the fiber cloth results in an inaccurate analysis of the relaxation loss of the CFRP cloth. This comes from large differences in the relaxation loss of the fiber cloth in the circumferential reinforcement positions, deformation of the anchor, and also deformation coordination between fibers.

Chinese scholars have investigated the relaxation properties of CFRP fabrics under axial tension. Wang et al. $[25,26]$ proposed the calculation equation of the prestress loss using the relaxation test of the CFRP specimen. Li et al. [27,28] studied the stress relaxation behavior of four CFRP fabric specimens under axial tension. They analyzed the effect of the prestress level on relaxation loss and proposed the 
time-dependent relaxation rate equation of CFRP fabric. Deng et al. [29] analyzed the stress relaxation test results of aramid fiber fabric under axial tension and proposed a equation for calculating the relaxation rate that changes with time using regression. The above literature has few considerations for the relaxation rate of the CFRP fabric under axial tensile conditions. This significantly limits the application of the calculation results.

Based on the aforementioned literature review and the aforesaid research deficiency, to make full use of the potential of CFRP and to understand the relaxation characteristics of prestressed CFRP cloth, an independently developed device was employed in this research to conduct six groups of stress relaxation tests that eliminate the slippage caused by CFRP cloth. Considering the effect of prestress level, CFRP cloth ruler, and glue treatment on relaxation performance, some measures were proposed to improve the relaxation rate. The relaxation rate equation of CFRP cloth was established and compared with other research results. The equation provides a reference for the application of CFRP as prestressed reinforcement material and for the improvement of its utilization efficiency in construction.

\section{Test Overview}

\subsection{Specimen Parameters and Material Mechanical Properties}

To study the relaxation performance of CFRP, the test was conducted at a constant temperature and constant humidity environment with a temperature of $20 \pm 2{ }^{\circ} \mathrm{C}$ and relative humidity of $55-60 \%$. In this experiment, six groups of test pieces were designed, with a total of 24 pieces. The tensile lengths of the test pieces were 600,1200 , and $2400 \mathrm{~mm}$, and the width of the cloth was $150 \mathrm{~mm}$. The prestress levels of each group were $0.1,0.2,0.28$, and $0.34 \mathrm{fu}$, respectively, and the last three groups of specimens were coated with glue. The parameters of the test pieces of each group are shown in Table 1. The CFRP used in the test and the impregnating adhesive matched with the CFRP are produced by Carbon Composites Co., Ltd., Tianjin, China. The CFRP model is CFS-I-300, and the single-layer thickness is $0.167 \mathrm{~mm}$. The dip adhesive consists of two-component: epoxy resin adhesive and curing agent, which were mixed with a 2:1 ratio (see Figure 1). The performance test of the CFRP cloth that was conducted in the 200-t universal testing machine is shown in Figure 2. The mechanical properties of the CFRP cloth and the impregnated adhesive are also presented in Table 2.

Table 1. Specimen parameters.

\begin{tabular}{cccccccc}
\hline No. & Specimen No. & L/mm & $\boldsymbol{\lambda}$ & No. & Specimen No. & L/mm & $\lambda$ \\
\hline \multirow{3}{*}{ I } & L6P1 & 600 & 0.1 & & GL6P1 & 600 & 0.1 \\
& L6P2 & 600 & 0.2 & & GL6P2 & 600 & 0.2 \\
& L6P28 & 600 & 0.28 & IV & GL6P28 & 600 & 0.28 \\
& L6P34 & 600 & 0.34 & & GL6P34 & 600 & 0.34 \\
\hline \multirow{4}{*}{ II } & L12P1 & 1200 & 0.1 & & GL12P1 & 1200 & 0.1 \\
& L12P2 & 1200 & 0.2 & \multirow{2}{*}{ V } & GL12P2 & 1200 & 0.2 \\
& L12P28 & 1200 & 0.28 & & GL12P28 & 1200 & 0.28 \\
& L12P34 & 1200 & 0.34 & & GL12P34 & 1200 & 0.34 \\
\hline \multirow{3}{*}{ III } & L24P1 & 2400 & 0.1 & & GL24P1 & 2400 & 0.1 \\
& L24P2 & 2400 & 0.2 & VI & GL24P2 & 2400 & 0.2 \\
& L24P28 & 2400 & 0.3 & & GL24P28 & 2400 & 0.3 \\
& L24P34 & 2400 & 0.34 & & GL24P34 & 2400 & 0.34 \\
\hline
\end{tabular}

Note: In GL6P1, G represents gluing treatment, L6 represents a tensile length of $600 \mathrm{~mm}$, and P1 represents a prestress level of 0.1 . 


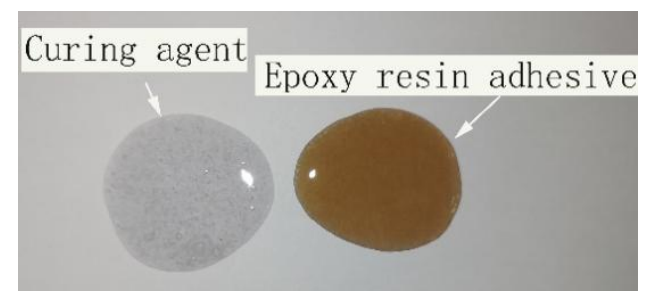

Figure 1. Dip adhesive.

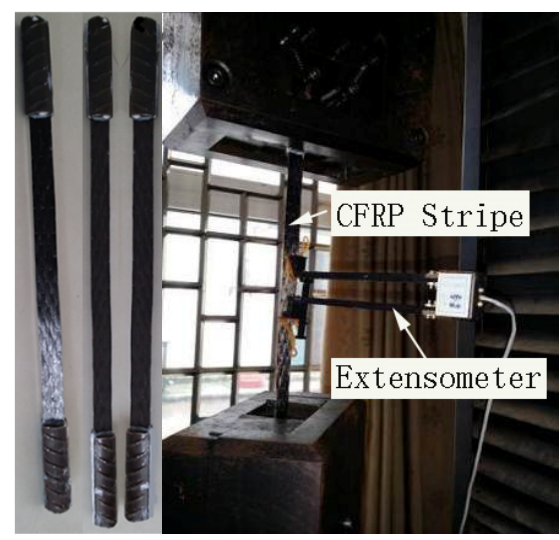

Figure 2. performance test of CFRP cloth.

Table 2. Properties of materials.

\begin{tabular}{cccc}
\hline Material Category & $f_{y} / \mathbf{M P a}$ & $\boldsymbol{E} / \mathbf{M P a}$ & $f_{c} / \mathbf{M P a}$ \\
\hline CFRP (sole fabric) & 3634 & $2.38 \times 10^{5}$ & - \\
Dip adhesive & 58 & 2584 & 78 \\
\hline
\end{tabular}

Note: The CFRP model is CFS-I-300; CFS, carbon fiber sheet; I, High-intensity level 1; 300, Carbon fiber cloth weighs $300 \mathrm{~g} / \mathrm{m}^{3}$.

To ensure the reliability of the test results, we pre-made four sets of L12P2 specimens and performed a $168 \mathrm{~h}$ relaxation test. The results demonstrate that the relaxation loss rate of the four sets of L12P2 specimens was almost the same (see Figure 3).

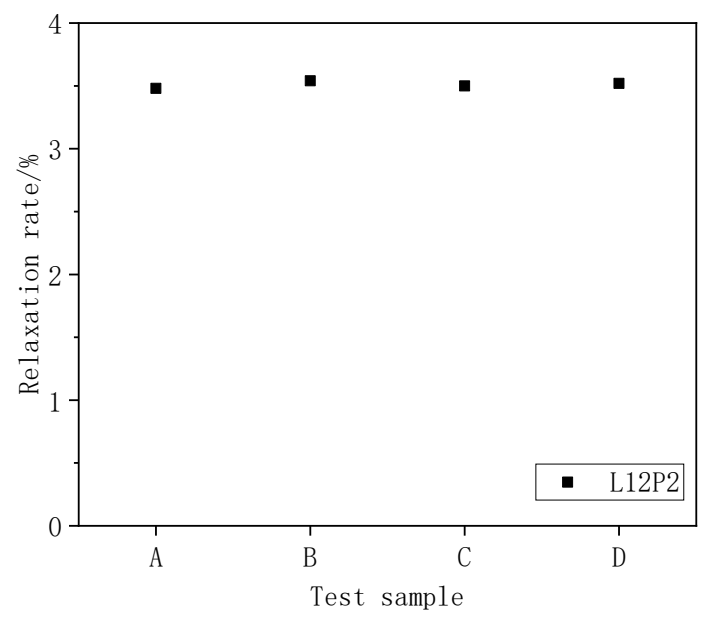

Figure 3. Test results of relaxation rate of L12P2 specimen.

For coating CFRP cloth, first, the CFRP cloth was put into the tensioning anchor on the new tensioning table for pre-tensioning. Moreover, kraft paper was placed under the tensioning device to avoid the impregnation of the adhesive gluing to the new tensioning device. Then, the impregnating 
adhesive was applied to the CFRP evenly. Finally, after the impregnating adhesive was initially set, the tension was applied to the CFRP cloth.

\subsection{Test Loading Method}

The test was conducted in the Guangxi Key Laboratory of Rock and Soil Mechanics and Engineering, using a newly developed tensioning device [30], as shown in Figure 4a. The device consists of a fixed end (for fixing self-locking anchors), a tension end (used to apply prestress), a base, and an LVDT (Linear Variable Differential Transformer), where the position of the base can be adjusted according to the lengths of the test specimen. The two ends of the device are fixed to the CFRP by embedding self-locking anchors (Figure 5a). The self-locking anchor is fixed on the tensioning table by using high strength pins, and then one end is tensioned. Prestressing of the CFRP fabric is completed by tightening the nut at the tension end using a wrench. The amount of the slippage between the CFRP and the anchor end is measured by the LVDT existing at both ends of the tension device.

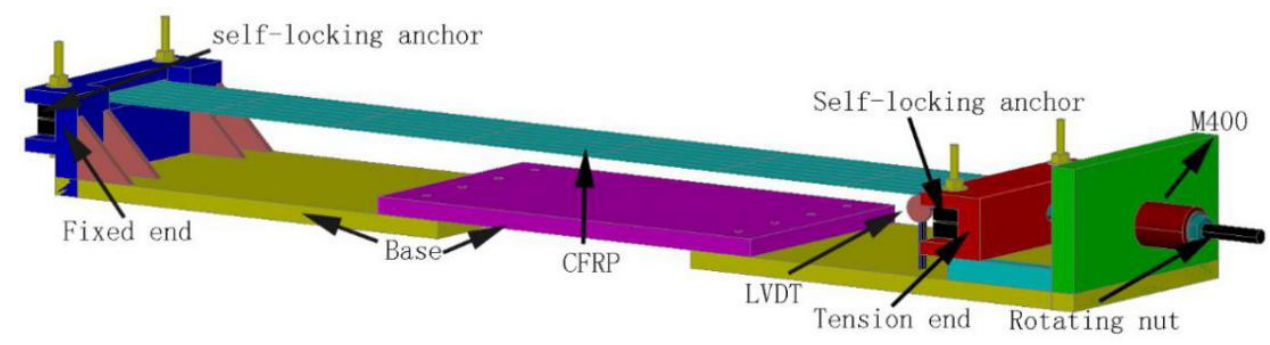

(a)

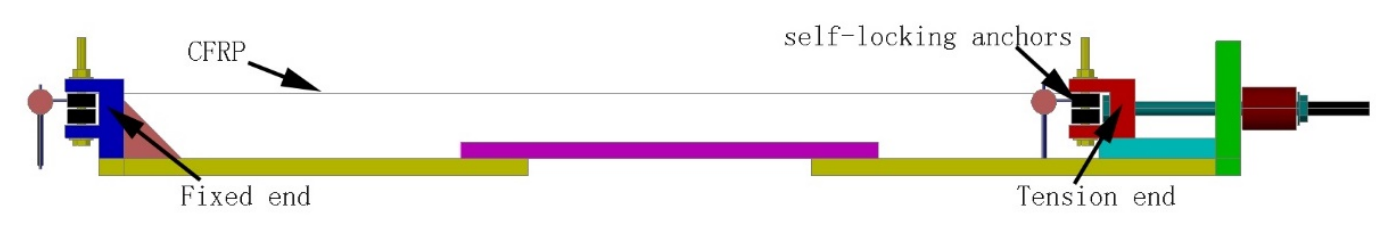

(b)

Figure 4. Prestressed CFRP cloth relaxation tensioning: (a) relaxation loss testing device of CFRP cloth; and (b) side view of the testing device.

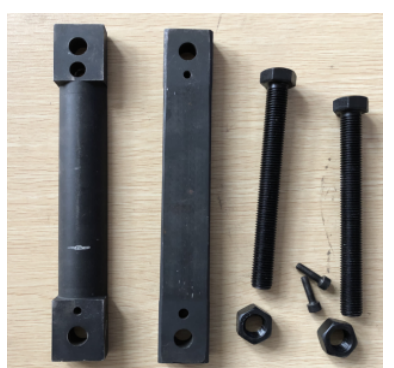

(a)

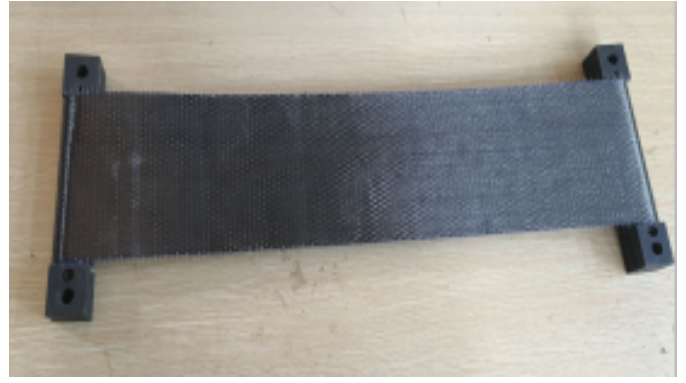

(b)

Figure 5. Picture of tension anchor: (a) anchorage; and (b) anchorage wrapped with a carbon fiber cloth.

\subsection{Test Measuring Method}

The strain gauges in this test were numbered from " 1 " at the tension end. Three strain gauges were arranged on the CFRP cloth of Groups I and IV (Figure 6a); five strain gauges were arranged on the specimens of Groups II and V (Figure 6b); and six strain gauges were arranged on the specimens of Groups III and VI (Figure 6c). The strain gauges were pasted on the CFRP cloth by ethyl $\alpha$-cyanoacrylate instant adhesive. The performance of CFRP cloth was not the same everywhere since CFRP cloth was a 
composite material woven from CFRP wire. To reduce this difference in performance, all strain gauges were pasted on the same group of CFRP wire. The strain gauges were connected to the DH3816 static resistance strain gauge Donghua Software Co., Ltd., Beijing, China. The control tension stress was measured by a force transducer and recorded by an M400 data acquisition system.

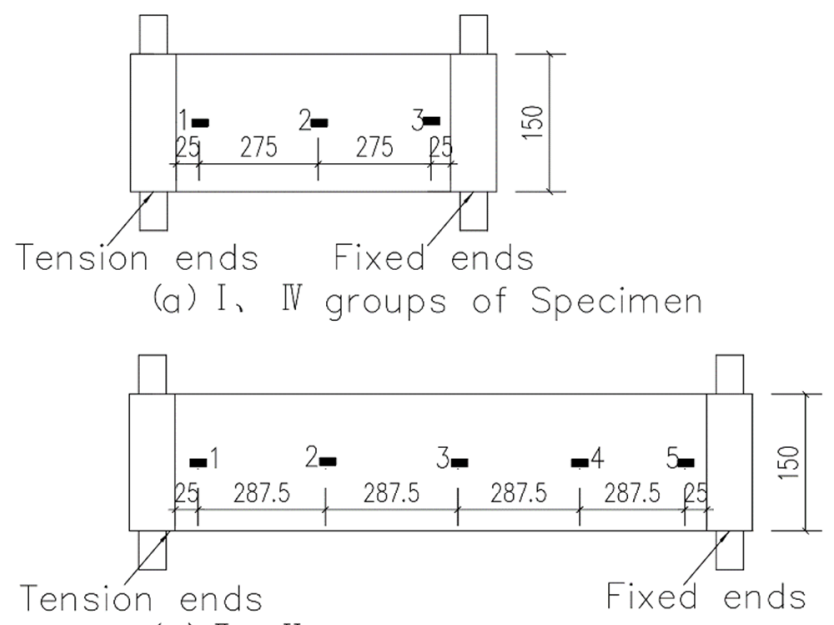

(b) II $V$ groups of Specimen

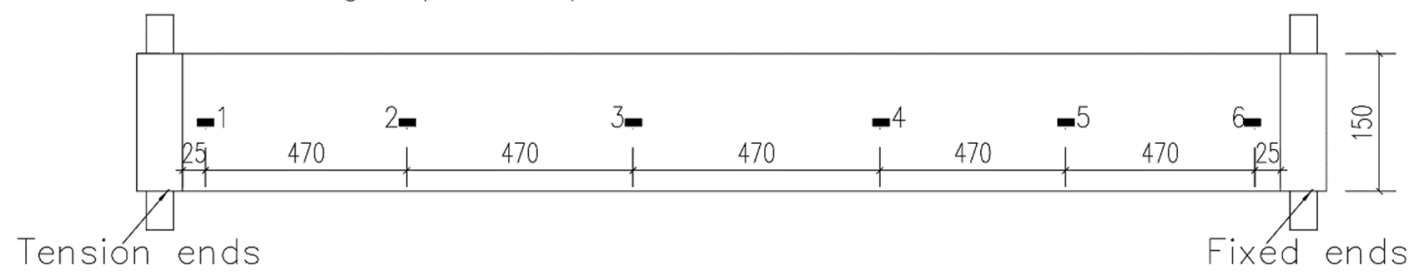

(c) $\mathbb{Z} 、$ VI groups of Specimen

Figure 6. (a-c) Schematic of strain gauge arrangement on fiber (unit: $\mathrm{mm}$ ).

Before starting the test, the balance between the displacement sensor and the static strain collection system was first set to zero. The slippage between the CFRP and the anchor end was the value measured $1 \mathrm{~h}$ after the tension was completed. The data collection interval was set to $1 \mathrm{~s}$, and then the wrench at the tension end was slowly rotated to apply prestress. When the prestress reached the set value, the prestress was no longer applied and the wrench was removed. In addition, the data collection interval was reset to $1 \mathrm{~min}$. After data collection for $8 \mathrm{~h}$, the collection interval was set to $1 \mathrm{~h}$ until the end of the test. Note that the whole test period was $168 \mathrm{~h}$.

\section{Test Results and Analysis}

\subsection{Stress Loss Analysis}

In the axial tension test of CFRP cloth, the measured stress loss $\sigma_{R}$ divided into two parts: (1) the relaxation caused by the CFRP cloth itself, $\sigma_{1}$; and (2) the CFRP slip between the CFRP and the anchor end, $\sigma_{2}$

$$
\sigma_{R}=\sigma_{1}+\sigma_{2}
$$

$\sigma_{2}$ caused by the slip between the CFRP and the anchor end is presented in Table 3 . According to past domestic and foreign code for design [31,32], the slippage stress is calculated according to Equation (2).

$$
\sigma_{2}=E \frac{\Delta_{S}}{l}
$$


Table 3. Slippage stress values.

\begin{tabular}{cccccc}
\hline Specimen No. & $\boldsymbol{\Delta}_{\boldsymbol{s}} / \mathbf{m m}$ & $\boldsymbol{\sigma}_{\mathbf{2}} / \mathbf{M P a}$ & Specimen No. & $\boldsymbol{\Delta}_{\boldsymbol{s}} / \mathbf{m m}$ & $\sigma_{2} / \mathbf{M P a}$ \\
\hline L6P1 & 0.02 & 8.03 & GL6P1 & 0.02 & 8.03 \\
L6P2 & 0.03 & 12.05 & GL6P2 & 0.03 & 12.05 \\
L6P28 & 0.043 & 17.27 & GL6P28 & 0.04 & 16.67 \\
L6P34 & 0.06 & 24.1 & GL6P34 & 0.055 & 22.09 \\
L12P1 & 0.024 & 4.82 & GL12P1 & 0.024 & 4.82 \\
L12P2 & 0.033 & 6.62 & GL12P2 & 0.033 & 6.62 \\
L12P28 & 0.039 & 7.83 & GL12P28 & 0.048 & 9.64 \\
L12P34 & 0.052 & 10.44 & GL12P34 & 0.046 & 9.24 \\
L24P1 & 0.026 & 2.61 & GL24P1 & 0.026 & 2.61 \\
L24P2 & 0.038 & 3.81 & GL24P2 & 0.035 & 3.51 \\
L24P28 & 0.036 & 3.62 & GL24P28 & 0.033 & 3.31 \\
L24P34 & 0.058 & 5.82 & GL24P34 & 0.052 & 5.22 \\
\hline
\end{tabular}

The test results indicate that, when the CFRP cloth length and prestress level increased, the slippage between the CFRP and the anchor end increased. The glue coating had little impact on the slippage of CFRP cloth.

The relaxation rate of the CFRP cloth is defined as the ratio of the relaxation loss of CFRP cloth, $\sigma_{1}$, to the initial stress, $\sigma_{c o n}$ and the calculation equation is as follows:

$$
\beta=\frac{\sigma_{1}}{\sigma_{c o n}}
$$

The test results are presented in Table 4.

Table 4. Stress relaxation loss $\beta$.

\begin{tabular}{|c|c|c|c|c|c|c|c|c|}
\hline Specimen No. & $\begin{array}{c}\sigma_{\text {con }} \\
/ \mathrm{MPa}\end{array}$ & $\begin{array}{l}\sigma_{1-24} \\
/ \mathrm{MPa}\end{array}$ & $\frac{\sigma_{1-24}}{\sigma_{1-168}} / \%$ & $\sigma_{1-100} / \mathrm{MPa}$ & $\frac{\sigma_{1-100}}{\sigma_{1-168}} / \%$ & $\begin{array}{l}\sigma_{1-168} \\
/ \mathrm{MPa}\end{array}$ & $\sigma_{f} / \mathrm{MPa}$ & $\beta / \%$ \\
\hline L6P1 & 381.26 & 11.70 & 86.45 & 13.13 & 97.02 & 13.53 & 367.73 & 3.54 \\
\hline L6P2 & 690.28 & 15.39 & 86.45 & 17.02 & 95.58 & 17.80 & 672.20 & 2.58 \\
\hline L6P28 & 927.56 & 16.21 & 87.45 & 17.91 & 96.58 & 18.54 & 908.46 & 2.00 \\
\hline L6P34 & 1161.39 & 26.17 & 86.45 & 29.01 & 95.73 & 30.30 & 1130.70 & 2.61 \\
\hline L12P1 & 385.65 & 18.19 & 87.35 & 20.09 & 96.50 & 20.82 & 364.83 & 5.39 \\
\hline L12P2 & 670.87 & 21.01 & 87.35 & 23.23 & 96.58 & 24.05 & 645.95 & 3.59 \\
\hline L12P28 & 967.79 & 27.34 & 88.35 & 30.13 & 97.38 & 30.94 & 936.06 & 3.20 \\
\hline L12P34 & 1161.85 & 39.45 & 86.24 & 44.14 & 96.50 & 45.74 & 1115.26 & 3.94 \\
\hline L24P1 & 395.24 & 20.52 & 84.98 & 23.71 & 98.23 & 24.14 & 371.10 & 6.10 \\
\hline L24P2 & 669.89 & 23.20 & 85.43 & 26.68 & 98.24 & 27.16 & 641.84 & 4.06 \\
\hline L24P28 & 999.15 & 33.72 & 88.35 & 36.93 & 96.78 & 38.16 & 960.84 & 3.82 \\
\hline L24P34 & 1161.26 & 47.07 & 85.35 & 53.85 & 97.64 & 55.15 & 1105.85 & 4.75 \\
\hline GL6P1 & 386.32 & 12.53 & 94.59 & 12.99 & 98.06 & 13.25 & 373.07 & 3.43 \\
\hline GL6P2 & 708.67 & 16.76 & 95.10 & 17.26 & 97.90 & 17.62 & 690.37 & 2.48 \\
\hline GL6P28 & 935.76 & 17.09 & 95.20 & 17.47 & 97.36 & 17.95 & 917.04 & 1.92 \\
\hline GL6P34 & 1186.89 & 28.17 & 94.63 & 28.69 & 96.38 & 29.76 & 1156.23 & 2.51 \\
\hline GL12P1 & 396.48 & 18.77 & 93.00 & 19.79 & 98.06 & 20.19 & 376.29 & 5.17 \\
\hline GL12P2 & 700.00 & 22.79 & 94.90 & 23.69 & 98.66 & 24.01 & 675.99 & 3.43 \\
\hline GL12P28 & 980.90 & 28.43 & 94.82 & 29.45 & 98.23 & 29.98 & 950.01 & 3.06 \\
\hline GL12P34 & 1190.37 & 42.56 & 95.38 & 43.45 & 97.38 & 44.62 & 1145.37 & 3.75 \\
\hline GL24P1 & 397.65 & 21.67 & 94.60 & 22.46 & 98.06 & 22.90 & 374.75 & 5.76 \\
\hline GL24P2 & 702.00 & 25.53 & 95.20 & 26.11 & 97.36 & 26.82 & 675.18 & 3.82 \\
\hline GL24P28 & 1020.78 & 34.81 & 94.82 & 36.07 & 98.23 & 36.72 & 983.28 & 3.60 \\
\hline GL24P34 & 1200.23 & 51.32 & 95.68 & 52.50 & 97.88 & 53.64 & 1146.36 & 4.47 \\
\hline
\end{tabular}




\subsection{Effect of Prestress Level on Relaxation Loss}

The relaxation curve of the test with the progress of time is shown in Figure 7. The analysis of Figure 7 and Table 4 suggests that:

(1) At the beginning of the test, the magnitude of stress relaxation of the CFRP fabric increased rapidly, and the relaxation rate raised promptly too. A shown in Figure 7a,c,e, the uncoated specimens could reach more than $85 \%$ of the final relaxation rate of the whole test period $(168 \mathrm{~h})$ just after $24 \mathrm{~h}$. Figure $7 \mathrm{~b}, \mathrm{~d}$, f shows that, after $24 \mathrm{~h}$, the glue-coated specimens could reach more than $95 \%$ of the final relaxation rate of $168 \mathrm{~h}$. Thereafter, the relaxation rate gradually grew and ultimately tended to become stable.

(2) It can be found that, when the relaxation rate was increased from 0.1 to $0.3 \mathrm{fu}$, the prestress level of the test pieces of the three groups decreased significantly. When the prestress level was increased to $0.34 \mathrm{fu}$, the decrease in the relaxation rate was reduced substantially. We argue that this was because, when the prestress level was between 0.1 and $0.3 \mathrm{fu}$, as the prestress level increased, the curved fibers in the specimens became straightened, and the performance of the fiber cloth was improved. The larger is the prestress level, the more obvious this improvement will be. Hence, the relaxation rate raised with the prestress. When the prestress level was increased to $0.34 \mathrm{fu}$, some of the shorter fibers in the fiber cloth were broken resulting in the reduction of the performance of the fiber cloth. At this time, if the prestress level was raised further, the working performance of the fiber cloth not only did not increase but also decreased. Therefore, the relaxation rate of the specimen grew continuously with the increase of the prestress level.

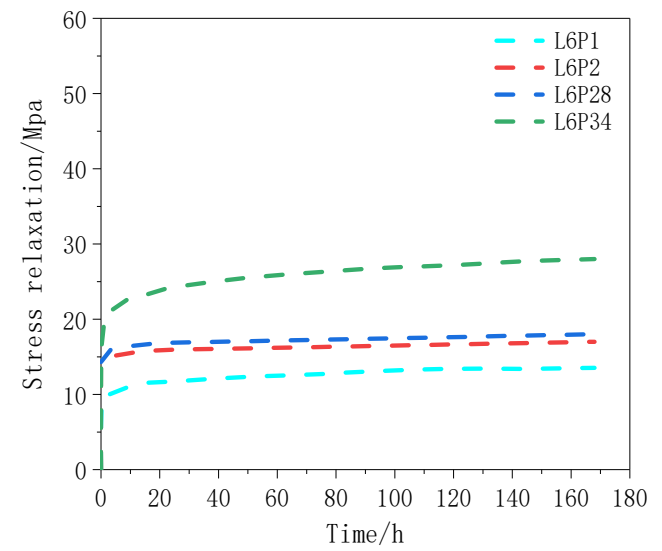

(a) The first group of test pieces

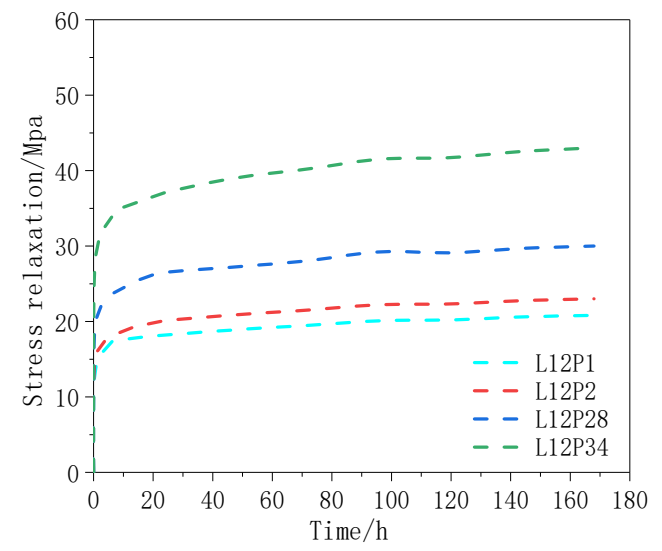

(c) The third group of test pieces

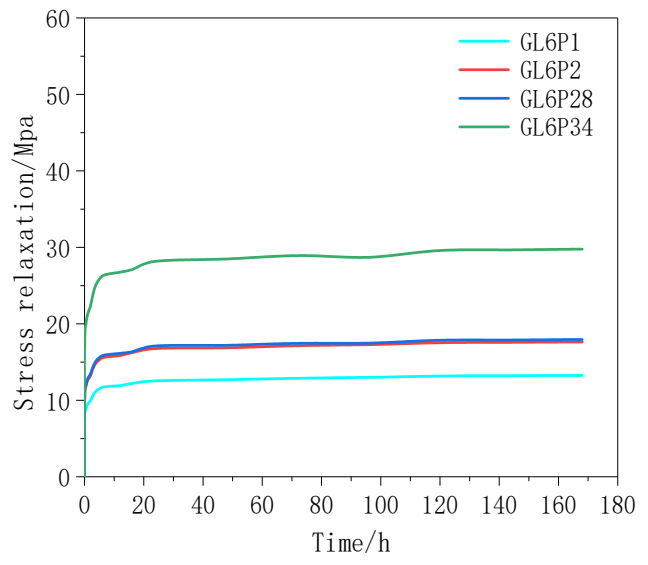

(b) The second group of test pieces

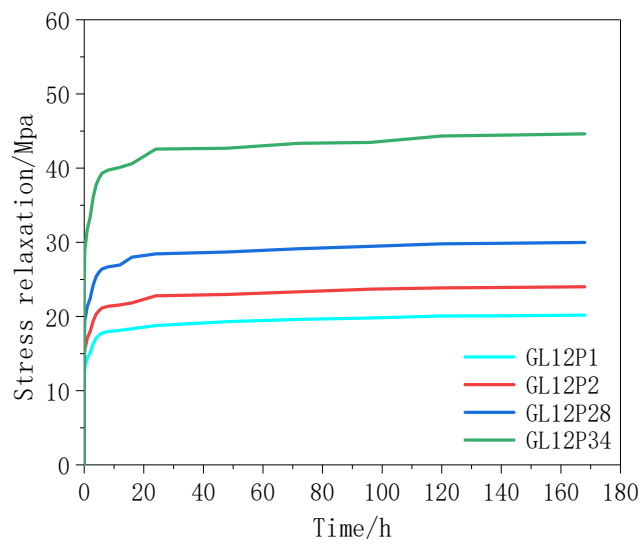

(d) The fourth group of test pieces

Figure 7. Cont. 


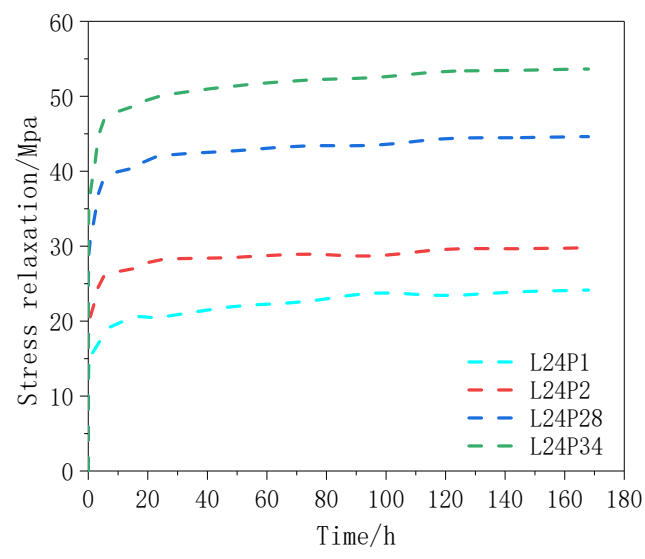

(e) The fifth group of test pieces

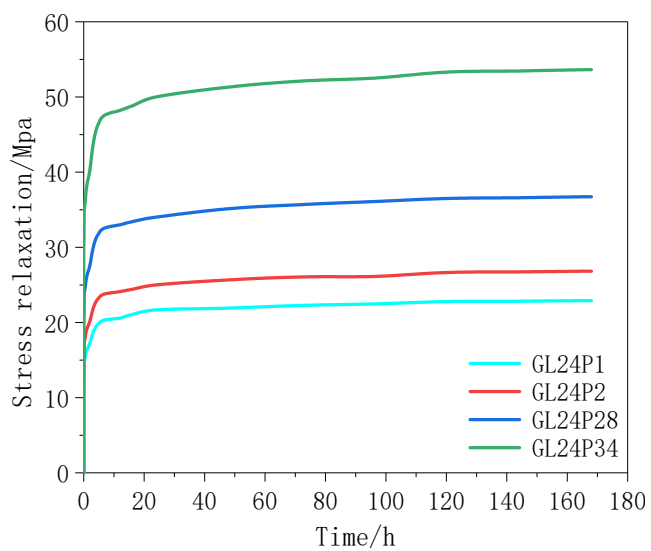

(f) The sixth group of test pieces

Figure 7. (a-f) Stress Relaxation loss-time relationship of CFRP cloth.

\subsection{Effect of Specimen Length on Relaxation Loss}

The curves of the relaxation rate vs. time obtained from the tests are shown in Figure 8 . The analysis of Figure 8 and Table 4 demonstrates that the relaxation rate became stable after $24 \mathrm{~h}$. At the same prestress level, the relaxation rate increased as the CFRP fabric length increased. This was because some of the constituent filaments had some defects such as insufficient straightness and short length, originating from the manufacturing process. As the length of the CFRP fabric increased, the stress loss caused by the defect increased accordingly.

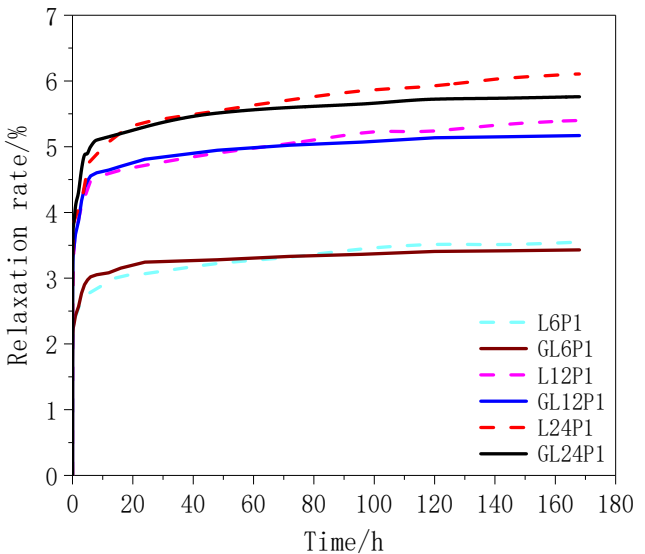

(a) $\lambda=0.1$ group of test pieces

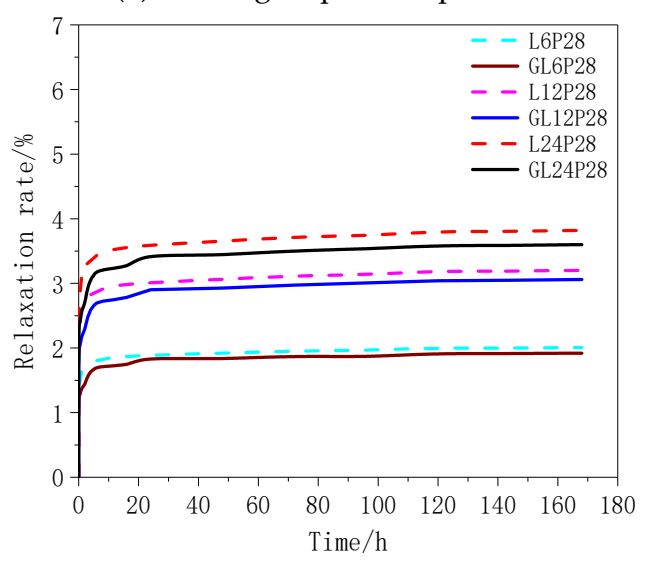

(c) $\lambda=0.28$ group of test pieces

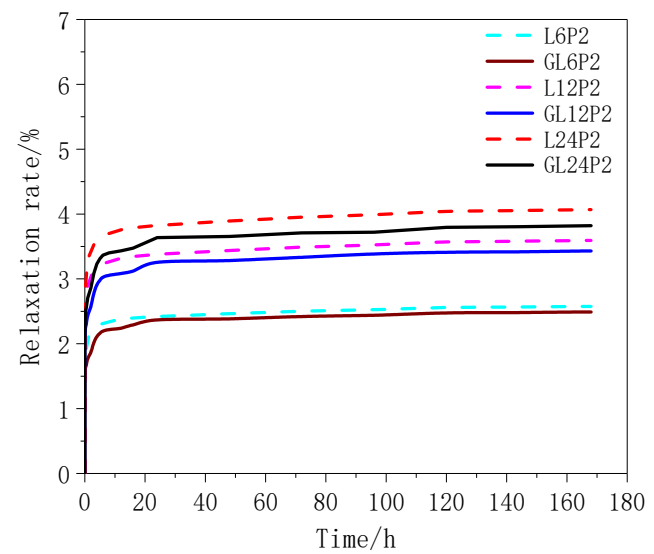

(b) $\lambda=0.2$ group of test pieces

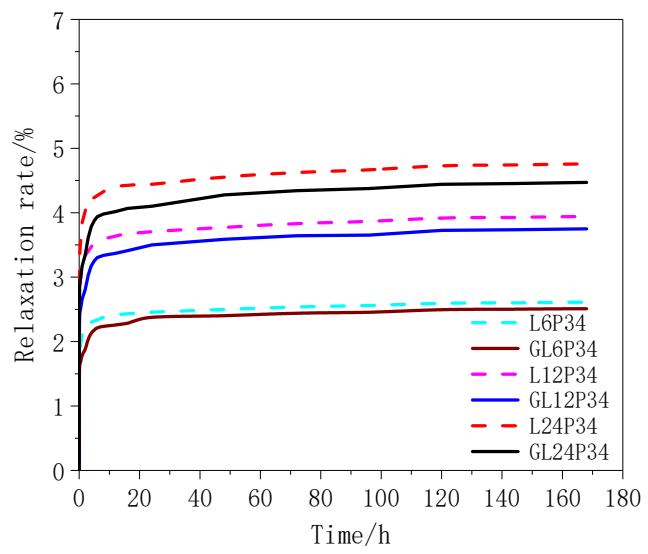

(d) $\lambda=0.34$ group of test pieces

Figure 8. (a-d) Relaxation rate-time relationship of CFRP cloth. 
Figure 9 shows a histogram of the relaxation rate of the test pieces after $168 \mathrm{~h}$ under different treatment methods. Because the surface of the test piece was glue-coated, the fiber cloth was evenly stressed. Thus, the shorter fibers did not break due to uneven stress, and the overall performance was better. Under the same cloth length, the curve of relaxation rate vs. pre-stress level of the glue-coated test pieces was in the form of "concave". With the rise of the prestress level from 0.28 to $0.34 \mathrm{fu}$, the relaxation rate of the test piece did not decrease but increased. Therefore, in engineering applications, when the prestress level is between 0.28 and $0.34 \mathrm{fu}$, coating the surface of the fiber cloth is useful for improving the performance of the fiber cloth.

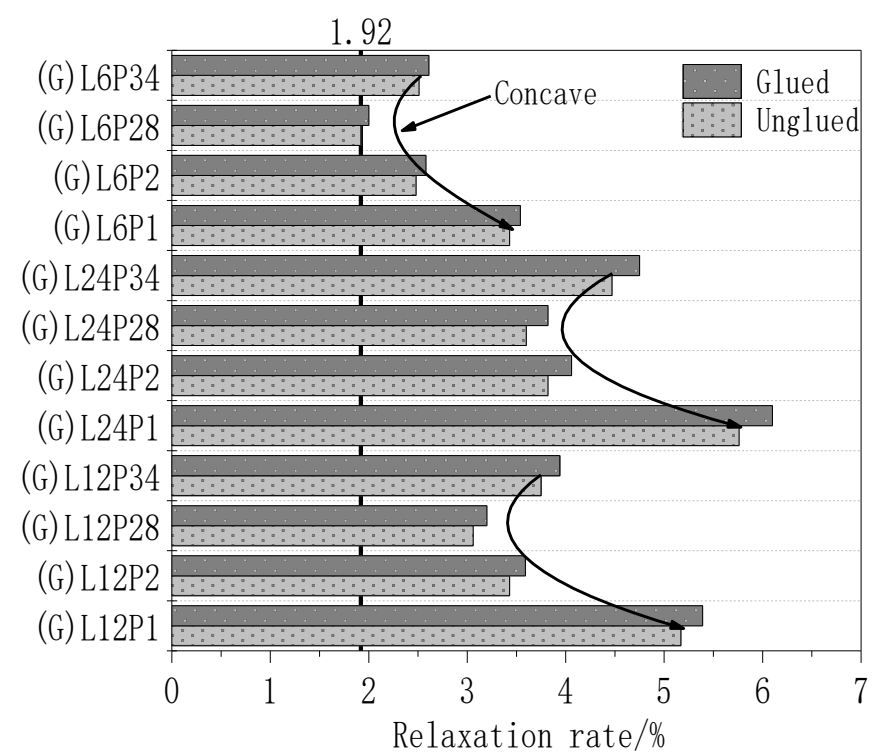

Figure 9. Post-168 h histogram of the relaxation rate of specimens under different treatments.

\subsection{Results Analysis of the Glue-Coated Test Pieces}

Table 5 shows a comparison between the results of different processing methods. After gluing, the relaxation rate of the test piece was reduced by up to $6.28 \%$.

Table 5. Comparison of the relaxation rate of the unglue specimen (subscripted " $u$ ") and the relaxation rate of the glue specimen (subscripted " $G$ ").

\begin{tabular}{ccccc}
\hline Specimen No. & $\beta_{u} / \%$ & Specimen No. & $\beta_{G} / \%$ & $\left(\frac{\beta_{u}-\beta_{G}}{\beta_{G}}\right) / \%$ \\
\hline L6P1 & 3.54 & GL6P1 & 3.43 & 3.21 \\
L6P2 & 2.58 & GL6P2 & 2.48 & 4.03 \\
L6P28 & 2.00 & GL6P28 & 1.92 & 4.17 \\
L6P34 & 2.61 & GL6P34 & 2.51 & 3.98 \\
L12P1 & 5.39 & GL12P1 & 5.17 & 4.26 \\
L12P2 & 3.59 & GL12P2 & 3.43 & 4.67 \\
L12P28 & 3.20 & GL12P28 & 3.06 & 4.58 \\
L12P34 & 3.94 & GL12P34 & 3.75 & 5.07 \\
L24P1 & 6.10 & GL24P1 & 5.76 & 5.90 \\
L24P2 & 4.06 & GL24P2 & 3.82 & 6.28 \\
L24P28 & 3.82 & GL24P28 & 3.60 & 6.11 \\
L24P34 & 4.75 & GL24P34 & 4.47 & 6.26 \\
\hline
\end{tabular}

\subsection{Relaxation Rate-Time History at Different Positions of Carbon Fiber Cloth}

Figure 10 exhibits the relationship between relaxation rate and time at different positions of the test pieces of each group. Here, only the control tension stress values at different positions of the horizontal test pieces under $0.1 \mathrm{fu}$ prestressed level are shown in Table 6 (control tension stress equal 
to strain gauge reading at the corresponding position times elastic modulus of carbon fiber cloth). The control tension stress at the tension end and the fixed end of the specimen were large, and the difference between the two was not significant. The control tension stress in the middle of the cloth was smaller than that of the end of the test piece. The reason was that when the prestress was applied at the tension end, a reaction force equal to the value of the force applied at the tension end was also generated at the fixed end. As a result, the control tension stress at the fixed end, and the tension end were almost equal. Because some carbon fibers in the carbon fiber cloth were not straight enough, and there were gaps between the carbon fibers, these defects induced during the manufacturing process made a certain loss in the transmission of force on the carbon fibers. The closer it is to the middle of the cloth strip, the larger this loss would be. Therefore, the control tension stress in the middle of the cloth was smaller than the control tension stress at both ends. By reducing the loss in the middle of the CFRP cloth, the relaxation of the CFRP cloth could be effectively reduced and the utilization efficiency of the prestressed CFRP could be improved.
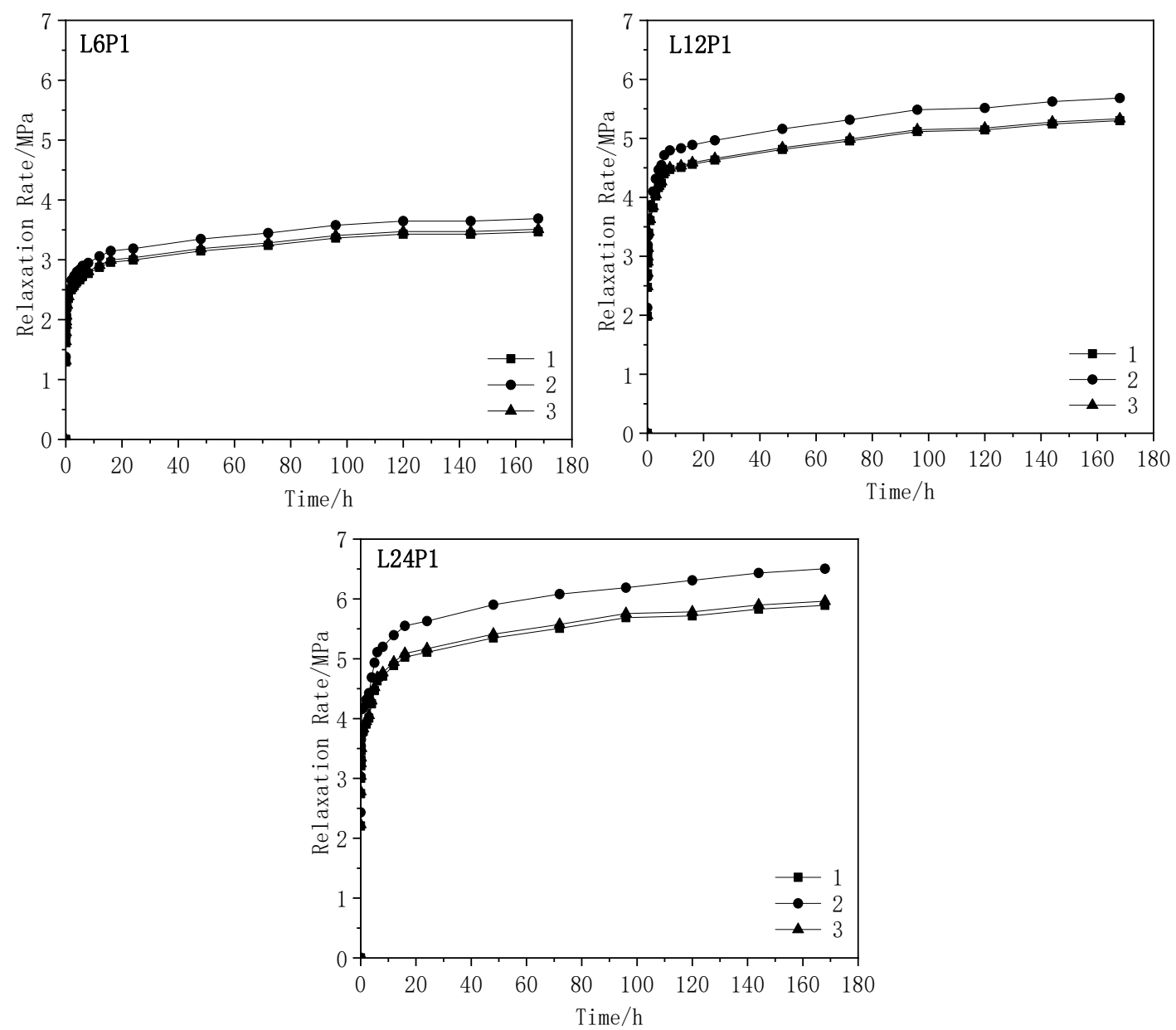

Figure 10. Time-dependent curves of relaxation rate at different locations of CFRP cloth.

Table 6. Control tension stress at different positions of the specimen (unit: MPa).

\begin{tabular}{cccc}
\hline Strain Gauge No. & L6P1 & L12P1 & L24P1 \\
\hline 1 & 390.42 & 392.83 & 409.7 \\
2 & 367.04 & - & - \\
3 & 385.6 & 366.32 & 371.14 \\
5 & - & 390.42 & \\
6 & - & - & 404.88 \\
\hline
\end{tabular}




\section{Calculation of Relaxation Rate}

\subsection{Shortcomings of Existing Relaxation Rate Equations}

$\mathrm{Li}$ [28] proposed a equation for CFRP cloth relaxation rate changing with time through a $168 \mathrm{~h}$ experimental study on four CFRP cloth specimens:

$$
\mathrm{Y}=\mathrm{a}+b \ln t
$$

where $\mathrm{Y}$ denotes the relaxation rate (\%) and $t$ stands for the time (h). $a$ and $b$ are statistically calculated based on the test results. The relaxation of CFRP fabrics develops fast in the early stage and tends to become gentle in the later stage. The coefficients $a$ and $b$ can be calculated through regression of the test results, and then the relaxation rate of CFRP fabrics in 10 and 50 years can be predicted accordingly. However, if the above equation is applied to calculate the relaxation rate of CFRP cloth, the coefficients $a$ and $b$ for each test piece are different, and, hence, its adaptability is poor.

In [25], based on the $2500 \mathrm{~h}$ experimental study on three CFRP cloth specimens, a CFRP cloth relaxation rate equation is proposed as follows:

$$
\beta=0.275 \frac{f_{p i}}{f_{p u}}-0.083
$$

where $\beta$ is the relaxation rate (\%) of CFRP cloth, $f_{p i}$ is the initial stress, and $f_{p u}$ is the ultimate tensile strength of the CFRP cloth. The prestress level has a significant influence on the relaxation rate of the CFRP cloth. However, the above equation only estimates the relaxation rate based on the prestress level, and the influential factors are poorly considered. Therefore, this relaxation rate equation is more in line with the aforementioned experimental results. However, it is not applicable to other experimental observations and, hence, its versatility is poor.

\subsection{A New Relaxation Rate Equation}

As mentioned above, the existing relaxation rate equations are generally not versatile due to weak consideration of the influencing factors. However, more consideration of the influencing factors makes the relaxation rate equation too complicated, which is not beneficial for guiding engineering practice. Based on the research results of $\mathrm{Wu}$ [33] combined with those obtained in this study (the relaxation rate of carbon fiber cloth with different prestress levels), the effect of the prestress level on the relaxation rate was clearly considered. Moreover, the influential factors of cloth length, time, and glue coating were introduced in the equation at the same time. The relaxation rates of carbon fiber cloth with different prestress levels are presented in Table 7.

Table 7. The relaxation rate of carbon fiber cloth with different prestressing levels.

\begin{tabular}{ccc}
\hline$\lambda$ & Relaxation Rate of This Study $\beta / \%$ & Relaxation Rate of Existing Test Results $\beta / \%$ \\
\hline 0.1 & 5.39 & - \\
0.2 & 3.59 & 3.64 \\
0.28 & 3.20 & - \\
0.3 & - & 3.23 \\
0.34 & 3.94 & - \\
0.4 & - & 3.97 \\
\hline
\end{tabular}

Note: For all data shown in the table, cloth length was $1200 \mathrm{~mm}$, test time was $168 \mathrm{~h}$, and the test piece was unglued.

Figure 9 shows that the relaxation rate of the test piece and the prestress level conform to a quadratic equation with one variable. Thus, it was assumed that the relationship of the relaxation rate with the prestress level, cloth length, time, and glue coating is as follows: 


$$
\beta=g \delta \gamma\left(a \lambda^{2}+b \lambda+c\right)
$$

where $\lambda$ is the prestress level, $\gamma$ is the influence coefficient of cloth length, $\delta$ is the influence coefficient of time, $g$ is the influence coefficient of glue coating, and $a, b$, and $c$ are undetermined constants.

Considering Equation (6), data analysis software (Origin, 2018C) was used to perform a non-linear regression analysis for the prestress level and relaxation rate data which are presented in Table 7 (refer to Figure 11). All undetermined constants could be obtained using this analysis (see Equation (7)). In the analysis, the fabric length $\gamma$ of $1200 \mathrm{~mm}$ was taken as $1, \delta$ was taken as 1 when the relaxation test time was $168 \mathrm{~h}$, and $g$ was taken as 1 when the surface of the test piece was untreated.

$$
\beta=\left(56 \lambda^{2}-32 \lambda+7.8\right)
$$

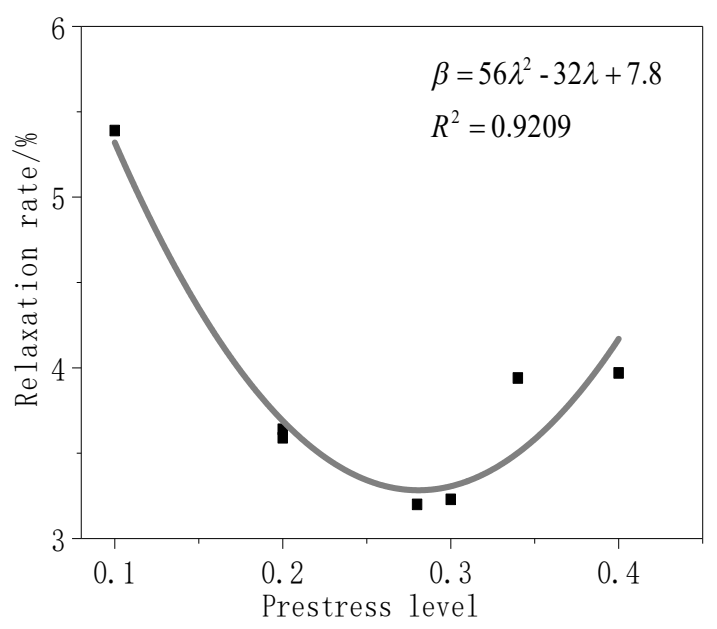

Figure 11. Relaxation curve.

With substituting the remaining testing results into Equation (6), the influence coefficient of the size on the relaxation rate after $168 \mathrm{~h}$ could be derived. When the specimen length was 600 and $2400 \mathrm{~mm}, \gamma$ was taken as 0.63 and 1.15 , respectively.

Based on the test results of this research combined with the equation proposed in [28], the relaxation rate of each test piece at different test times could be calculated. When the test time was $2500 \mathrm{~h}, 10$ years, and 50 years, $\delta$ was taken as $1.04,1.21$, and 1.30 , respectively.

For the time being, there are few studies on the relaxation rate of CFRP cloth coated with glue. According to the test results of this research, the influence coefficient $g$ of glue coating was taken as $0.962,0.955$, and 0.942 when the length of the test piece was 600,1200 , and $2400 \mathrm{~mm}$, respectively.

\section{Comparison of Calculated and Experimental Results}

\subsection{Comparison of the Calculated Values of the Relaxation Rate with Those of the Experimental Results}

To validate the relaxation rate calculation method proposed in this research, the calculated relaxation rates were compared with the experimental results obtained in this study, as indicated in Table 8. As is evident, the relaxation rates calculated by the proposed equation were in good agreement with the experimental results such that the degree of dispersion is minor. This suggests that the equation established in this research is appropriate for other similar tests as well $\beta_{e} / \beta_{c}$. 
Table 8. Comparison of relaxation test values and calculation values.

\begin{tabular}{cccccccc}
\hline $\begin{array}{c}\text { Specimen } \\
\text { No. }\end{array}$ & $\begin{array}{c}\text { Calculated } \\
\text { Relaxation } \\
\text { Rate } \boldsymbol{\beta}_{\boldsymbol{e}} / \boldsymbol{\%}\end{array}$ & $\begin{array}{c}\text { Test } \\
\text { Relaxation } \\
\text { Rate } \boldsymbol{\beta}_{\boldsymbol{c}} / \boldsymbol{\%}\end{array}$ & $\boldsymbol{\beta}_{\boldsymbol{e}} / \boldsymbol{\beta}_{\boldsymbol{c}}$ & $\begin{array}{c}\text { Specimen } \\
\text { No. }\end{array}$ & $\begin{array}{c}\text { Calculated } \\
\text { Relaxation Rate } \\
\boldsymbol{\beta}_{\boldsymbol{e}} / \boldsymbol{\%}\end{array}$ & $\begin{array}{c}\text { Test } \\
\text { Relaxation } \\
\text { Rate } \boldsymbol{\beta}_{\boldsymbol{c}} / \boldsymbol{\%}\end{array}$ & $\boldsymbol{\beta}_{\boldsymbol{e}} / \boldsymbol{\beta}_{\boldsymbol{c}}$ \\
\hline L6P1 & 3.25 & 3.54 & 0.92 & GL6P1 & 3.38 & 3.43 & 0.99 \\
L6P2 & 2.58 & 2.24 & 1.15 & GL6P2 & 2.38 & 2.48 & 0.96 \\
L6P28 & 2 & 2.04 & 0.98 & GL6P28 & 2.12 & 1.92 & 1.10 \\
L6P34 & 2.61 & 2.48 & 1.05 & GL6P34 & 2.22 & 2.51 & 0.89 \\
L12P1 & 5.16 & 5.39 & 0.96 & GL12P1 & 5.40 & 5.17 & 1.05 \\
L12P2 & 3.59 & 3.64 & 0.99 & GL12P2 & 3.81 & 3.43 & 1.11 \\
L12P28 & 3.2 & 3.23 & 0.99 & GL12P28 & 3.38 & 3.06 & 1.11 \\
L12P34 & 3.94 & 3.56 & 1.11 & GL12P34 & 3.55 & 3.75 & 0.95 \\
L24P1 & 5.93 & 6.10 & 0.97 & GL24P1 & 6.30 & 5.76 & 1.09 \\
L24P2 & 4.06 & 4.19 & 0.97 & GL24P2 & 4.44 & 3.82 & 1.16 \\
L24P28 & 3.82 & 3.73 & 1.02 & GL24P28 & 3.94 & 3.6 & 1.10 \\
L24P34 & 4.75 & 4.24 & 1.12 & GL24P34 & 4.14 & 4.47 & 0.93 \\
& AV & & 1.01 & & AV & & 1.03 \\
& SD & & 0.077 & & SD & & 0.094 \\
& COV & & 0.075 & & COV & & 0.091 \\
\hline
\end{tabular}

\subsection{Comparison of Different Tests Results}

Wang et al. [25] conducted a prestress loss test on reinforced concrete beams reinforced with four prestressed CFRP cloths. The fiber cloth length was $1200 \mathrm{~mm}$, the cloth width was $140 \mathrm{~mm}$, the thickness was $0.167 \mathrm{~mm}$, the tensile strength was $3522 \mathrm{MPa}$, and the elastic modulus was $259 \mathrm{GPa}$. The prestress level was set to $0.28,0.30,0.36$, and $0.4 \mathrm{fu}$, and the whole test time was $2500 \mathrm{~h}$. This study only considered the stress loss results of three CFRP fabric test pieces after curing with epoxy resin for $72 \mathrm{~h}$. For the test pieces that release prestress immediately after being stretched to the design prestress level, no comparison can be made here because of the small number of test pieces (one piece). In Table 9, it can be observed that the results of the relaxation rate equation proposed in this study were in good agreement with the test results in [24], with a maximum deviation of 1.11. This indicates that the proposed relaxation rate equation could accurately predict the relaxation loss of reinforced concrete beams reinforced by the post-tensioned CFRP cloth.

Table 9. Comparison of experimental results in different literature.

\begin{tabular}{|c|c|c|c|c|c|c|}
\hline Author & $\begin{array}{c}\text { Specimen } \\
\text { No. }\end{array}$ & $\lambda$ & Time/h & $\begin{array}{c}\text { Documented } \\
\text { Relaxation } \\
\text { Rate } \beta_{c} / \%\end{array}$ & $\begin{array}{c}\text { Calculated } \\
\text { Relaxation } \\
\text { Rate } \beta_{e} / \%\end{array}$ & $\beta_{e} / \beta_{c}$ \\
\hline \multirow{3}{*}{ Wang [25] } & BPC-30-1 & 0.36 & \multirow{3}{*}{2500} & 3.9 & 3.6 & 0.92 \\
\hline & BPC-40-1 & 0.40 & & 3.6 & 4.0 & 1.11 \\
\hline & BPC-30-2 & 0.28 & & 3.7 & 3.3 & 0.89 \\
\hline \multirow{5}{*}{ Huang [19] } & 1 & 0.20 & \multirow{5}{*}{480} & 4.25 & \multirow{3}{*}{3.82} & 0.90 \\
\hline & 2 & 0.20 & & 3.85 & & 0.99 \\
\hline & 3 & 0.2 & & 4.21 & & 0.91 \\
\hline & 4 & 0.30 & & 3.32 & \multirow{2}{*}{3.4} & 1.02 \\
\hline & 5 & 0.30 & & 3.41 & & 1.00 \\
\hline \multirow{2}{*}{ Li [28] } & 1 & 0.45 & \multirow{2}{*}{168} & 5.364 & \multirow{2}{*}{4.741} & 0.88 \\
\hline & 2 & 0.45 & & 4.772 & & 0.99 \\
\hline \multicolumn{6}{|c|}{ AV } & 0.96 \\
\hline \multicolumn{6}{|c|}{ SD } & 0.069 \\
\hline \multicolumn{6}{|c|}{$\mathrm{COV}$} & 0.072 \\
\hline
\end{tabular}

Huang et al. [19] conducted 25 tests on reinforced concrete beams reinforced by prestressed CFRP slab. The specimens were divided into five groups, and each group had five specimens. Considering 
the effect of one-time over-tension and two-time over-tension on the test results, this research only compared the experimental and calculated results of one-time over-tension. The CFRP board was $1600 \mathrm{~mm}$ long, $100 \mathrm{~mm}$ wide, $0.23 \mathrm{~mm}$ thick, with a tensile strength of $3500 \mathrm{MPa}$, and an elastic modulus of $240 \mathrm{GPa}$. The prestress level was set to 0.2 and $0.3 \mathrm{fu}$, and the entire test time was $480 \mathrm{~h}$. Since the CFRP board length was $1600 \mathrm{~mm}$, the size influence coefficient $\gamma$ was obtained by interpolation $(\gamma=1.05)$. By considering the calculated results of Table 9 , it can be observed that the relaxation rates calculated by the proposed equation in this research had small deviations from the experimental results in [19]. The introduction of the size influence coefficient could even further reduce the discrepancies existing between experimental and calculated relaxation rates.

$\mathrm{Li}$ et al. [28] conducted four relaxation tests on prestressed CFRP fabrics. The tensile strength of CFRP fabrics was $3490 \mathrm{MPa}$ and the elastic modulus was $220 \mathrm{GPa}$. The prestress level was set to 0.45 and $0.5 \mathrm{fu}$, and the total test time was $168 \mathrm{~h}$. Table 9 suggests that, when the prestress level was $0.45 \mathrm{fu}$, the values of the relaxation rate predicted by the equation proposed in this research had a little deviation from the experimental results mentioned in [28]. When the prestress level was $0.5 \mathrm{fu}$, the deviation was larger. This was because, with the increase of the prestress level, the stress redistribution caused by the broken shorter fibers in the CFRP fabric was intensified, and, thus, the stress loss increased. Since the largest prestress level of the test piece in this study was 0.34 , the derived relaxation rate equation could not accurately calculate the relaxation rate when the prestress level was $0.5 \mathrm{fu}$.

\section{Conclusions}

To understand the relaxation behavior of prestressed CFRP fabric under axial tension, six sets of stress relaxation tests were conducted in a constant temperature and humidity environment with a temperature of $20 \pm 2{ }^{\circ} \mathrm{C}$ and relative humidity of $55-60 \%$. Through the analysis of the experimental results, the following conclusions could be drawn:

(1) The relaxation rate of CFRP cloth was between $1.92 \%$ and $6.1 \%$.

(2) After $24 \mathrm{~h}$, the relaxation rate of CFRP cloth could reach more than $85 \%$ of the final relaxation rate of the whole test time $(168 \mathrm{~h})$. When the prestress level was less than $0.3 \mathrm{fu}$, the curved fibers in the CFRP cloth were straightened so that the performance of the CFRP cloth was fully enhanced and the relaxation rate decreased when the prestress level was increased. When the prestress level was greater than $0.3 \mathrm{fu}$, some fibers were broken. Thus, the stress redistribution occurred, and the relaxation rate increased as the prestress level was increased.

(3) As the size of CFRP fabric increased, defects such as insufficient straightness and short length caused during the fabrication process raised the stress loss. It was observed that, at the same prestress level, the relaxation rate decreased by a maximum of $47.6 \%$.

(4) The relaxation loss was reduced by gluing of the test piece, and the relaxation rate was also diminished by $3.11-5.89 \%$ due to gluing. After the gluing treatment, the fiber cloth was evenly stressed, and the shorter fibers were not broken due to uneven stress. Hence, fiber cloth integrity was improved. In engineering practice, the size of the fiber cloth should be appropriately increased, and the pre-stress level should also be increased. In addition, the surface of the fiber cloth should be coated with glue to reduce the relaxation loss and to increase the effective prestress, which is advantageous for enhancing the reinforcement effect.

(5) According to the test results analysis, there were gaps between the sole carbon fabric after the prestress was applied. Moreover, there was a certain loss during the stress transmission process which made the CFRP cloth end stress greater and the middle stress smaller.

(6) The results of the equation established in this research can be used to predict the relaxation rate of CFRP cloth. These results were in good agreement with the experimental results. The deviation of the predicted results from the experimental results existing in the literature was small and the degree of dispersion was minor too. Therefore, the new equation proposed in this study can effectively predict the relaxation rate of the CFRP cloth. 
Author Contributions: Literature search, conception or design of the work methods, validation, data analysis, review and editing, C.-L.L.; Study design, data analysis, data interpretation, writing and revising, Q.W.; Data analysis, data interpretation, writing and revising, H.-L.S.; Supervision, data interpretation, data analysis, W.-X.Z.; Investigation, data analysis, J.-Z.H. All authors have read and agreed to the published version of the manuscript.

Funding: The authors gratefully acknowledge the financial support provided by Guangxi Natural Science Foundation (No. 2019GXNSFAA245055), Key R \& D projects in the Guangxi Autonomous Region (No. AA18118008), GuangXi Key Laboratory of New Energy and Building Energy Saving (No. 19-J-21-18), and Guilin University of Technology doctoral research fund.

Conflicts of Interest: The authors declare no conflict of interest. he funders had no role in the design of the study; in the collection, analyses, or interpretation of data; in the writing of the manuscript, or in the decision to publish the results

\section{Nomenclature}

$\begin{array}{ll}\text { AV } & \text { Average value } \\ \text { COV } & \text { Coefficient of variation } \\ f_{y} & \text { Modulus of elasticity of materials } \\ f_{c} & \text { Tensile strength of materials } \\ f_{u} & \text { compressive strength of materials } \\ \mathrm{L} & \text { Ultimate strength of materials } \\ \mathrm{SD} & \text { Tensile length of specimen } \\ \lambda & \text { Standard deviation } \\ \Delta_{S} & \text { Prestress level of CFRP } \\ \sigma_{c o n} & \text { The slippage between the CFRP and the anchor end } \\ \sigma_{f} & \text { Control tension stress of the CFRP cloth } \\ \sigma_{R} & \text { Eliminate loss of stress caused by relaxation, effective } \\ \sigma_{1} & \text { stress, } \sigma_{f}=\sigma_{\text {con }}-\sigma_{1-168} \\ \sigma_{2} & \text { Measured stress loss of the CFRP cloth } \\ \sigma_{1-24} & \text { Stress of the relaxation loss of the CFRP cloth } \\ \sigma_{1-100} & \text { between the CFRP and the anchor end } \sigma_{2}=E \frac{\Delta_{s}}{l} \\ \sigma_{1-168} & \text { Stress of the relaxation loss of the CFRP cloth in } 24 \mathrm{~h} \\ \beta & \text { Stress of the relaxation loss of the CFRP cloth in } 168 \mathrm{~h} \\ \beta_{c} & \text { Relaxation rate of the CFRP cloth } \\ \beta_{e} & \text { Test relaxation rate of the CFRP cloth } \\ \beta_{G} & \text { Calculate relaxation rate of the CFRP cloth } \\ \beta_{u} & \text { Relaxation rate of glue application specimen } \\ & \text { Relaxation rate of unglue application specimen }\end{array}$

\section{References}

1. Cai, H.W.; Aref, A.J. On the design and optimization of hybrid carbon fiber reinforced polymer-steel cable system for cable-stayed bridges. Compos. Part B Eng. 2015, 68, 146-152. [CrossRef]

2. D'Antino, T.; Pellegrino, C. Bond between FRP composites and concrete: Assessment of design procedures and analytical models. Compos. Part B Eng. 2014, 60, 440-456. [CrossRef]

3. Elrefai, A.; West, J.S.; Soudki, K. Performance of CFRP tendon-anchor assembly under fatigue loading. Compos. Struct 2007, 80, 352-360. [CrossRef]

4. Faleh, H.; Al-Mahaidi, R.; Shen, L.M. Fabrication and characterization of nano-particles-enhanced epoxy. Compos. Part B Eng. 2012, 43, 3076-3080. [CrossRef]

5. Kim, D.J.; Lee, J.; Lee, Y.H. Effectiveness factor of strut-and-tie model for concrete deep beams reinforced with FRP rebars. Compos. Part B Eng. 2014, 56, 117-125. [CrossRef]

6. Koo, J.M.; Choi, J.H.; Seok, C.S. Prediction of post-impact residual strength and fatigue characteristics after impact of CFRP composite structures. Compos. Part B Eng. 2014, 61, 300-306. [CrossRef]

7. Mufti, A.A. FRPs and FOSs lead to innovation in Canadian civil engineering structures. Constr. Build. Mater. 2003, 17, 379-387. [CrossRef] 
8. Neto, P.; Alfaiate, J.; Vinagre, J. A three-dimensional analysis of CFRP-concrete bond behavior. Compos. Part B Eng. 2014, 59, 153-165. [CrossRef]

9. Pham, T.M.; Hao, H. Impact Behavior of FRP-Strengthened RC Beams without Stirrups. J. Compos. Constr. 2016, 20, 04016011. [CrossRef]

10. Hassan, R.; Youssef, O.; Mills, J. Seismic Performance of Precast Post-Tensioned Segment FRP-Confined and Unconfined Crumb Rubber Concrete. J. Compos. Constr. 2017, 21, 04017006. [CrossRef]

11. Sundar, N.; Raghunath, P.N.; Dhinakaran, G. Flexural behavior of RC beams with hybrid FRP strengthening. Int. J. Civ. Eng. Technol. 2016, 7, 427-433.

12. Raoof, S.M.; Koutras, L.N.; Bournas, D.A. Textile-reinforced mortar (TRM) versus fiber-reinforced polymers (FRP) in the flexural strengthening of RC beams. Constr. Build. Mater. 2017, 151, 279-291. [CrossRef]

13. Lu, C.L.; Zhang, Z. Review on prestress lossof frp in reinforcement system. J/OL. Guilin Univ. Technol. 2020, 1-11.

14. Saadatmanesh, H.; Tannous, F.E. Long-term behavior of aramid fiber reinforced plastic (AFRP) tendons. Aci. Mater. J. 1999, 96, 297-305.

15. Tannous, F.E. Relaxation, creep, and fatigue behavior of carbon fiber reinforced plastic tendons. Aci. Mater. J. 1999, 96, 143-153.

16. Gunnarsson, A. Bearing Capacity, Relaxation and Finite Element Simulation forPrestressed Concrete Beams Reinforced with BFRP Tendons. Master's Thesis, Reykjavik University, Reykjavík, Iceland, 2013.

17. Shi, J.; Wang, X.; Huang, H.; Wu, Z. Relaxation behavior of prestressing basalt fiber-reinforced polymer tendons considering anchorage slippage. J. Compos. Mater. 2016, 51, 1275-1284. [CrossRef]

18. Guo, X.Y.; Zhong, M.J.; Jin, H.; Huang, P.Y. Experimental Study of Pre-stress Loss of RC Beam Strengthened by Pre-tensioned Pre-stressing CFL. J. Exp. Mech. 2016, 31, 141-148.

19. Huang, J.; Huang, P.; Zheng, X. Experimental study of prestress losses of RC beams strengthened with prestress FRP. J. Build. Struct. 2015, 36, 85-91.

20. Kim, Y.J.; Wight, R.G.; Green, M.F. Flexural Strengthening of RC Beams with Prestressed CFRP Sheets: Development of Nonmetallic Anchor Systems. J. Reinf. Plast. Compos. 2010, 29, 1277-1294. [CrossRef]

21. Costa, I.; Barros, J. Prestress Losses in NSM-CFRP Flexurally Strengthened RC Beams. Strain 2015, 51, 276-287. [CrossRef]

22. Zhou, C.; Li, J.; Zhu, W.; Yang, F. Design of Self-locking Anchor System of FRP and Research on Mechanical Properties. J. Build. Struct. 2013, 34, 141-148.

23. Lu, C.L.; Liu, C.C.; Wu, Y.S.; Wang, P.; Li, Z.Y. Experimental study on prestress loss of concrete circular columns strengthened with prestress cfrp sheets. J. Highw. Transp. Res. Dev. 2018, 35, 41-48.

24. Lu, C.L.; Wu, Y.S.; Wang, Q.; Liu, C.C.; Li, Z.Y. Experimental research on the prestressing loss of square concrete columns strengthened with prestressed cfrp sheets. Ind. Constr. 2017, 47, 41-46.

25. Wang, W.W.; Dai, J.G.; Zhang, L. Study on prestress loss test and calculation method of reinforced concrete beams strengthened with post-tensioned CFRP sheets. Proc. Civ. Eng. 2012, 11, 88-94. [CrossRef]

26. Wang, W.W.; Dai, J.G.; Harries, K.A.; Bao, Q.H. Prestress Losses and Flexural Behavior of Reinforced Concrete Beams Strengthened with Posttensioned CFRP Sheets. J. Compos. Constr. 2012, 16, 207-216. [CrossRef]

27. Li, S.H. Construction technology for reinforced concrete beams strengthened with prestressed CFRP. Constr. Technol. 2004, 33, 60-62.

28. Li, S.H. Experimental study on stress relaxation of carbon fiber cloth. Build. Struct. 2009, 4, 72-75.

29. Deng, Z.C.; Li, J.H.; Zhang, J.J.; Niu, K.; Liu, C.G. Experimental study on stress relaxation of aramid fiber cloth. Build. Struct. 2008, 6, 110-112.

30. Lu, C.L.; Wang, Q.; Wu, Y.S. A device for testing the stress relaxation of FRP cloth. China Patent CN205607767U, 28 September 2016.

31. China Communications Press. JTG 3362-2018 Code for Design of Highway Reinforced Concrete and Prestressed Concrete Bridges and Culverts; China Communications Press: Beijing, China, 2018. 
32. American Association of State Highway and Transportation Officials. LRFD Bridge Design Specifications; American Association of State Highway and Transportation Officials: Washington, WA, USA, 2005.

33. Wu, Y.S. Experimental Study on Prestress Loss of Concrete Columns Strengthened with Prestressed CFRP Sheets. Master's Theses, Gui Lin University of Technology, Guilin, China, 2017.

(C) 2020 by the authors. Licensee MDPI, Basel, Switzerland. This article is an open access article distributed under the terms and conditions of the Creative Commons Attribution (CC BY) license (http://creativecommons.org/licenses/by/4.0/). 